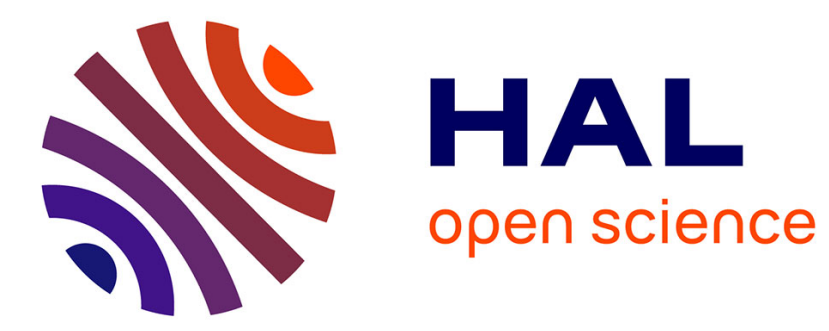

\title{
How to make biodiversity knowledge compelling? The case of mosquito control implementation in the Camargue (France)
}

\author{
Fanny Guillet, Laurent Mermet
}

\section{- To cite this version:}

Fanny Guillet, Laurent Mermet. How to make biodiversity knowledge compelling? The case of mosquito control implementation in the Camargue (France). Environmental Science \& Policy, 2020, 113, pp.64-71. 10.1016/j.envsci.2017.05.004 . hal-03116981

\section{HAL Id: hal-03116981}

\section{https://hal-agroparistech.archives-ouvertes.fr/hal-03116981}

Submitted on 20 Jan 2021

HAL is a multi-disciplinary open access archive for the deposit and dissemination of scientific research documents, whether they are published or not. The documents may come from teaching and research institutions in France or abroad, or from public or private research centers.
L'archive ouverte pluridisciplinaire HAL, est destinée au dépôt et à la diffusion de documents scientifiques de niveau recherche, publiés ou non, émanant des établissements d'enseignement et de recherche français ou étrangers, des laboratoires publics ou privés. 


\title{
How to make biodiversity knowledge compelling? The case of mosquito control implementation in the Camargue (France)
}

\author{
Fanny Guillet \\ Centre of ecology and conservation sciences, National museum of natural History \\ Laurent Mermet \\ Centre of ecology and conservation sciences, National museum of natural History
}

\section{Corresponding author:}

Fanny Guillet

Email: fguillet@mnhn.fr

Centre des Sciences de la Conservation, MNHN

CP 135, 43 rue Buffon,

75005 Paris, FRANCE

Tel: 0033.1.40.79.57.64.

\begin{abstract}
Despite the expressed desire for 'evidence based policy', especially in the environmental field, many policies seem to ignore available knowledge and to put aside scientific evidence. The science-policy interface, therefore, has abundant examples showing that knowledge production and decisionmaking processes should be analysed together. In this regard, we address the question of how biodiversity scientists could participate in social and political negotiation so that scientific biodiversity knowledge becomes evidence. We use the use of Bti for mosquito control in the Camargue, South of France, as an empirical case study to examine the place of biodiversity in the decision-making process and the role of scientists supporting biodiversity conservation. We demonstrate that to become evidence, scientific knowledge has to be widely adopted by stakeholders. In that context, biodiversity scientists have to keep demonstrating impacts on biodiversity to maintain the controversy opened. They also have to propose and eventually test alternative solutions. Combining actor-network theory and strategic analysis, our approach encourages social scientists to adopt casebased long-term field studies to contribute to reflections by biodiversity scientists as they struggle to make their work impact biodiversity policy.
\end{abstract}

Key words: biodiversity scientists, strategy, interface science and policy, mosquito-control, Camargue (France).

\section{Introduction}

The loss of biodiversity has appeared on the agenda at all political levels. Science and scientific practices are central to biodiversity conservation, from the formulation of the problem to developing solutions (Takacs, 1996). Despite this success in setting the political agenda, many biodiversity scientists are frustrated as they consider the continued loss of biodiversity and the slow, erratic or even negative progress of many conservation initiatives (Gordon, 2006). Many of them implicitly or explicitly express a view of the relationship between scientific knowledge and decision-making 
processes that could be roughly summarized as: "producing adequate knowledge to solve decision makers' problems is enough to bridge the science-policy gap" (Bradshaw and Brochers 2000; Loreau 2006). This view seems to be mirrored by policy-making institutions that express a willingness to improve scientific input into policy development (Juntti et al., 2009), for instance through building the IPBES, which implicitly suggests that better knowledge will lead to increased consideration of biodiversity in decision-making. This view is criticized as "naïve" by van den Hove (2007), corresponding to a 'technical-rational model' based on a positivist epistemology (Clark and Majone, 1985; Adelle et al., 2012) that does not account for the real processes of the science-policy interface. Indeed, many scholars, especially in the field of science studies, have shown that the relationship between knowledge and policy is far from linear (Jasanoff, 2004; Sarkki et al., 2015). Those who see scientific evidence as facts, or even as truth, often express surprise that such evidence is so often contradicted by policy decisions or used strategically and symbolically to legitimize decisions taken on other (political, organizational) grounds. In a review of the science studies literature, Juntti et al. (2009) establish three dimensions that have to be taken into account to understand the link between scientific evidence and policy-making: (1) the nature of evidence (depending on the methods used, on the sources and level of its scientific and social validity); (2) the normative dimension of the policies under consideration (scientific evidence depends on the way problems are framed); and (3) the role of power. To illuminate the route from science to policy, Michel Callon and Bruno Latour (Callon, 1986; Latour, 2005) propose reversing the logic that goes from science to policy and to reason on the basis that fact becomes evidence only once there is a collective agreement on it and to draw consequences from it.

This change of perspective can shed light on the challenges that currently face biodiversity scientists. It suggests that the main issue may no longer be producing robust knowledge that can be trusted to then be integrated into the policy-making process. The main question may be instead: how can scientists participate in the social and political negotiation so that biodiversity science knowledge becomes evidence? Through their specific stance, the challenge faced by biodiversity scientists is, therefore, to combine knowledge creation with participation in framing conservation issues and negotiating the solutions. How do they do that? Can they do it deliberately and strategically? And if so, what concepts can help them in such deliberations and strategy-building? This article aims to explore these questions, both to provide additional insights into the question of the place of scientific evidence in the policy-making process and to create a space for strategic reflection among the community of biodiversity scientists.

Specifically, we examine a case study of the mosquito-control controversy in the Camargue. Until 2005, because of its value for biodiversity conservation, the Camargue had remained, for decades, the only area without mosquito control along the entire coast from Marseille to the Spanish border (Claes-Mekdade and Nicolas, 2009). However, responding to pressures from tourism professionals, as well as local inhabitants, the Regional ark councils then agreed to implement "experimental mosquito control" over an initial five-year test period (2006-2011). The idea was that if, over this experimental period, biodiversity scientists found that mosquito control adversely affected biodiversity, it should be stopped. Biodiversity scientists did indeed demonstrate impacts, validated by the scientific community through peer-reviewed publications; however, local officials decided, regardless, to continue mosquito control after 2011. This case is examined since 2010, enabling us to analyse precisely the position of biodiversity scientists. A first statement was produced in 2013 (Guillet \& Mermet, 2013) in which it was explained how biodiversity scientists worked to integrate knowledge on biodiversity into the debate, but how this was not sufficient to influence the local policy, despite the initial political commitment. It is worth following up the analysis to appreciate the position of biodiversity scientists in this very common situation where their evidence was not taken into account within decision and territorial management policy. 
Our aim in this paper is to provide insights into the strategic role of biodiversity scientists underpinning knowledge production and interactions with policy-making processes. Section 2 presents our mixed framework based on two theories that appear both necessary and complementary to answer our question. Section 3 describes the case study with its successive steps with respect to both the biodiversity scientists' position and the decision-making process regarding mosquito control. Finally, section 4 discusses the important role of biodiversity scientists even when knowledge seems to be initially ignored.

\section{Theoretical framework and methodology: understanding scientists' strategy through the actor-network theory}

To shed light on how biodiversity scientists try to make knowledge influence policies favouring biodiversity conservation, we propose combining two theoretical perspectives.

The first, actor-network theory (ANT) (Callon, 1986; Akrich et al., 2006), focuses primarily on the science-policy interface. One of its major tenets is that facts are not directly uncovered by science as states of nature, but are built through collective agreement, in a process that is at the same time a debate about the facts and a negotiated reordering of the social-natural arrangements linked to these facts (a point eloquently advocated by Latour in his book Science in action, 1987). When the network (one of the ANT concepts used to designate this social arrangement) is formed around a fact, that fact becomes reality. Another interesting concept in the theory is that it encourages us to consider non-humans and humans on an equal ("symmetrical") footing when analysing their interests and position in the system, i.e. not to separate, artificially, natural, technical and political considerations when accounting for decision-making processes. Two somewhat different developments of the theory seem to us to be of particular relevance for environmental management and biodiversity conservation.

On the one hand, Bruno Latour's Politics of Nature (2004) presents the integration of a new environmental issue as the renegotiation of social-natural arrangements through the political deliberation of a (social-natural) political collective. For the issue to be successfully taken into account, the deliberation has to pass through successive phases: perplexity (is it really an issue?), consultation (what might solutions be, and who stands to win or lose what?), hierarchization (the actual negotiation of concrete changes in the social-natural system, including the painful choices it implies), institutionalization (once the issue is taken into account through the changes made, these become the natural state of affairs, both in terms of social rules and of scientific knowledge).

On the other hand, Michel Callon's (1986) translation theory focuses on the possibility that an innovation can reconfigure the social-natural arrangement (thereby resolving an environmental issue). By proposing an innovation (for instance, a technical innovation), the innovator invites stakeholders to satisfy their needs through the innovation rather than through the means they are hitherto using. They will do so if (and only if) the innovation embodies a better understanding of their needs, and solution to them, than do existing solutions. This constitutes the translation process: each stakeholder finds the innovation to be a useful rendition of (and solution to) his needs. Here again the process goes through phases: problematization (hypothesizing that the innovation may answer the stakeholders' problems), engagement (convincing some of them that innovation is worth trying), enrolment (actually experimenting using the innovation with some of them), and then finally mobilization of allies (if the experiment has succeeded, it still remains to be seen if the innovation will be adopted widely by a large number of users). 
In both versions - centred on political deliberation, or on an innovation - throughout the process, issues of politics and issues of knowledge are negotiated alongside one another, as the two faces of one process.

As we demonstrate below, this first theoretical perspective, a contrast to the linear view of scientific facts feeding political decisions, is a useful complement to enrich biodiversity scientists' reflection on the science-policy interface.

This approach, however, needs to be complemented by a second, more strategic perspective, one that reflects the efforts of biodiversity scientists to ensure that biodiversity is taken into account in decision-making processes, often in the face of significant resistance. Strategic environmental management analysis (Mermet, 2011) assumes that biodiversity conservation outcomes are the result of strategic actions wherein "environmental actors" who prioritize biodiversity conservation have to work hard to make other actors improve their practices or modify their projects which have an environmental impact. Strategy is defined as a combination of specific intentions with the aim of changing a given situation (Lorino and Tarondeau, 2006). Every strategy is embedded in a negotiation context, in that fundamental antagonisms and oppositions among actors are inevitable, whether or not they are explicit. Strategic action aims to bypass, mitigate or suppress such antagonisms (Crozier and Friedberg, 1980). If one links together actor-network theory and strategic management analysis, the strategy of biodiversity scientists would be considered successful if they can find and implement a strategy such that the actor-network consolidates itself around biodiversity conservation solutions.

Both perspectives - ANT and strategy - demand highly context-dependant analyses: ANT because it is only by following, in detail, the multiple place- and case-specific negotiations through which the social-natural arrangement is brought to change, in which one can observe the fine inter-weaving of political and scientific processes; strategic analysis because strategy exists only in real-life situations where interests are at stake.

Thus having a case study as a starting point is particularly relevant to explore the kind of issues we plan to discuss here (Yin, 2003). We focus on the case of mosquito control in the Camargue over a number of years, through a qualitative approach involving semi-structured interviews and document analysis (Olivier de Sardan, 1995). Interviews aimed at recording the views and interpretations of different stakeholders about the mosquito-control implementation, their own interests and position in the network and also the kind of resources each one has available to develop their strategies. Document analysis targeted all kinds of document produced around the issue, including position papers, prefectural decrees, press articles, annual activity or scientific reports as well as scientific publications. This analysis aims to identify information that is publicly available and examines official problematization of the issue. The analysis finally cuts across the two types of field material.

Information on administrative divisions in France is necessary in order to understand the case study. France is divided into regions, which represent local government. These regions are administered by Departments, which have specific competences such as mosquito control. Finally, all municipalities of the Camargue are members of the natural regional park. Local officials of both the municipalities and the relevant Department of Bouche-du-Rhône lead the park through its governing council. We undertook a first wave of survey activity in 2010-2011, involving 15 interviews with stakeholders at the local level: biodiversity scientists, people from the Regional park, the mosquito control operator called Entente Interdepartementale de démoustication (EID), and local decision-makers. Between 2012 and 2015, some follow-up interviews were conducted with three to five key informants. In 2016, we undertook a second wave of survey activity, involving a series of 15 interviews. Some interviews were with the same local stakeholders and others with new informants at the regional level, since the situation has evolved to involve a larger geographic area and a wider set of stakeholders. 


\section{Results}

\subsection{Opening act: policy unexpectedly turns a deaf ear to science}

Until the late 1990s, there was a widely-shared consensus to leave the Camargue outside the mosquito-control zone, mainly for ecological reasons. The tourism industry, however, expressed repeated demands for mosquito control to be implemented in the Camargue Regional Park. At the end of the 1990s, as a new biological pest control (using the bacteria Bacillus thuringiensis Bti) came on the market as a replacement for non-selective phosphate insecticides, the park unlocked the door by agreeing to consider the possibility of extending mosquito control to the Camargue. Feeling that the barrier to mosquito control was near to being removed, biodiversity scientists and natural areas managers entered the debate and obtained from decision-makers the following guarantee: if impacts on biodiversity were demonstrated, the mosquito control would be stopped. This condition was thus formalized in the regional park charter, which promises to "recommend the stop or the limitation of mosquito-control if potential impacts are proven". The Region is committed to "support mosquitocontrol if protected areas are strictly saved".

In the aftermath of an exceptional mosquito outbreak in the autumn of 2005, local decision-makers in the Regional park council decided to start the first mosquito control cycle from 2006 to 2011. This mosquito control was presented as experimental because it was for a limited time (five years), it was combined with a research programme examining biodiversity impacts, and its possible continuation beyond the five years was conditional on the absence of demonstrated biodiversity impacts. The Regional Park organized the research program through a call for tenders. Biodiversity scientists choose to participate in this study despite the high scientific challenge of such an operation. Indeed, impacts of Bti on biodiversity had never been demonstrated before and studying this phenomenon in real field conditions was a difficult exercise, with a high risk of failing to demonstrate impact, whether or not it actually existed. During this period, the operator implementing the mosquitocontrol was asked to be more transparent about its practices, such as the relevant period of treatment and the necessary area of dispersion around a breeding habitat.

After five years of experimental mosquito control, biodiversity scientists had obtained remarkable research results, demonstrating impacts on several biological groups. Intake of Nematocera (Diptera sub-order including midges and mosquitoes) and their predators (spiders and dragonflies) decreased significantly at treated site, causing food web perturbation and then the decline of bird breeding success (Poulin et al., 2010a; Poulin et al., 2010b). Bti treatment causes a decrease in species richness (Jacob and Poulin, 2016). However, despite the initial political commitment to interrupting or strongly limiting mosquito control if there were proven impacts on biodiversity, and despite five years of meaningful research results, the Regional Park council (including local decision-makers) decided that "experimental" mosquito-control should be continued on the same basis, to meet the local demand and that an independent research programme should be pursued as well to obtain more convincing evidence of the impacts.

This outcome contradicts the widely-shared expectation that facts demonstrated by science would inform policy-making. It is particularly striking here because policy-makers had initially stated that they were willing to be informed by biodiversity research and to modify their decision according to research results, and because they had funded the research programme accordingly. In our account of this decision after our first wave of the survey (Guillet and Mermet, 2013), we pointed out that whereas the linear ("science informs policy-making") model failed to explain this outcome, a strategic perspective was more useful. In 2005, decision-makers would have had to pay a high political cost if they had imposed mosquito-control with no consideration of its possible biodiversity impacts, confronting directly the active and influential biodiversity conservation interest group in the Camargue. The decision to launch a five-year experimental programme was a very rational strategic 
move on their part, if one considers the two possible outcomes. Either the scientists could have failed to demonstrate biodiversity impacts: in that case, opposition to mosquito-control would have been diffused at a very low political cost. In the eventuality that (as actually happened) scientists did manage to demonstrate impacts, after five years of the increased comfort provided by mosquitocontrol, the power relations between proponents and opponents would have shifted in a way that would greatly decrease the political cost of overcoming opposition to mosquito control.

Finally, the hierarchization (Latour, 2004) has failed and the first round of negotiation did not lead to concrete changes in the social-natural system. Our second round of survey completes this analysis by showing that the controversy about the reality of biodiversity impacts has reopened during the years after 2011 and intensified in 2015 when the 2016 mosquito control campaign was about to be prepared. In view of the high cost of mosquito-control for the Camargue (around 1 million euro/year for 9000 inhabitants) and of the reductions in available budgets, departmental officers started considering the idea of reducing mosquito control. As soon as local officials heard about this possibility, they strongly defended mosquito control through phone calls, appointments with officials, etc. They argued that inhabitants of the Camargue should be considered as every other human being and had a right to comfort where they live. Departmental officials had to organize an ad hoc meeting to reassure local officials and inhabitants that mosquito control would be continued. Commenting on this event, interviewees explain that biodiversity is not the central issue, as the evidence of impacts is not yet established.

"The debate on impacts is not closed. There is no clear picture of impact on the food chain. Biodiversity scientists say that there are impacts. The operator says that impacts are no more that marginal' (Departmental office, interview 2016).

"There are plenty of studies on Bti and lots of publications. It is highly controversial. Bti is an approved product presenting the lowest possible impact among products available on the market. But I also heard that it could have more impacts than some products we used before" (mosquito-control operator, interview 2016).

Here, ideas from ANT complement strategic analysis as they account for the fact that many stakeholders will not consider "facts" to be demonstrated as long as they themselves have not decided to implement concrete changes in behaviour and decisions based on those facts: deciding on facts does not precede making a decision about what to do, but proceeds in parallel, alongside it.

This first round of decision-making and research (2005-2011) may leave the impression of an impasse, and of a failure for biodiversity scientists. However, the 2011-2016 period has seen new developments that allow us to acquire a deeper understanding of the science-policy interface, a wider view of the strategies available to biodiversity scientists, and to realize that the game may not be finished, despite impressions to the contrary.

\subsection{From policy deliberation to technical innovation: can the mosquito trap become a compelling passage point?}

The first series of new developments revolves around the initiative to promote a technical innovation: the mosquito trap. The principle of the trap is to emit carbon dioxide and pheromones that lure, attract and destroy mosquitoes, which are hunting for humans to bite.

The same biodiversity scientists involved in the Bti impacts research programme initiated interest in this possible alternative method to reduce the nuisance due to mosquitoes. Feeling that inhabitants were getting accustomed to the nuisance reduction and that interrupting mosquito control would be politically difficult, towards the end of the 2005-2011 experimental period, they started testing mosquito-traps around their own offices. Their hope was that if the traps proved effective, they could provide a way of controlling the nuisance from mosquitoes without destroying massive insect populations. Targeting only biting insects, and only in very limited inhabited areas, they would deliver effectiveness in terms of comfort for people comparable to Bti, but without the biodiversity impacts. 
Since then, interest in this possible solution has been gradually building. Local engineers with an entrepreneurial mindset and good political connections have espoused the idea and have been working on perfecting mosquito trap models adapted to the local conditions in the Camargue. Some local officials have supported their initiative as one promising locally based economic development. The Region, which discontinued its funding of mosquito control from 2012 because of biodiversity impacts, has expressed an interest in funding this alternative solution using environmental-policy funds. The regional park has funded the experimental installation and testing of traps.

A first field test was conducted in 2015 in a village at the centre of the Camargue. Inhabitants were satisfied until there was a major outbreak in September combined with wind that blew mosquitoes in the direction of the village. Inhabitants then wondered if traps were attracting mosquitoes instead of constituting the expected barrier. A second test was undertaken in 2016, with additional and betterplaced traps. It was more conclusive and convinced the residents.

"The trap located near my house is very effective: I can eat outside again in the evening". "This technique is great!

When will we have it in Salin-de-Giraud? And in Arles?' (Comments on the Facebook page created

for the test, 2016)

These developments represent the adoption of a very different strategy by biodiversity scientists. Instead of relying on knowledge to change policy decisions through public debate, they used technical innovation that, if adopted, would transform the technical, social and natural arrangement in a way that would resolve the issue raised by the biodiversity impacts of Bti.

Here it is possible to identify Callon's model of how an innovation can transform a situation. If the mosquito trap is found to be compelling enough by the various actors, they will adopt it and, de facto, resolve the issue of mosquito control impact on biodiversity.

The first two stages - problematization and engagement - have been successfully negotiated: the biodiversity scientists have promoted the hypothesis that the mosquito trap could satisfy the inclinations of the stakeholders by providing, simultaneously, high levels of comfort, low or zero biodiversity impact, and possibly lower costs; and various stakeholders have, indeed, expressed interest.

The 2015 and 2016 tests represent entry into the third phase of the "translation" process as described by Callon, as the stakeholders actively participate in tentatively experiencing an arrangement transformed around the new technology. Promoting the mosquito trap promotes a new framing of the problem and a clear change from the previous framing - "should we do mosquitocontrol or not?" - to a new one - "can we undertake mosquito control in a way that has no biodiversity impact?"

In these developments we recognize two aspects of the situation that are often met in discussions of biodiversity conservation issues. (1) There are many cases in which a technical innovation (agroforestry, biological pest control, etc.) is felt to offer a potential for major changes, since, at least in principle, it could satisfy different preoccupations of stakeholders who currently oppose one another about decisions regarding the technologies currently in use. (2) Such situations are also often analysed as if conflict between conservationists and their opponents were the result of poor framing of the issues and could be resolved through intelligent reframing.

An important contribution of Callon's translation model here is to insist that neither new technologies nor reframing can change a situation by themselves: they can do so only if they are compelling enough, i.e. if all the relevant stakeholders adopt them and stop what they currently do, and if they do so on a large scale, not only in pilot experiments (Billé, 2010).

In the Camargue, some crucial steps - designated as the mobilization of allies by M. Callon - have not been played out yet. The consolidation of the network will have to rely on building further the relationship between Department and local officials and the mosquito trap company, the latter having to propose a convincing business model that will solve public budget problems. The network 
will also be strengthened if biodiversity responds positively to the installation of mosquito traps. Biodiversity scientists still represent biodiversity by studying impacts of mosquito traps and verifying that only targeted insects are attracted (Poulin, 2015: only $0.7 \%$ of the trapped insects were nontarget species). But most of all, the network will consolidate around a solution to control mosquitoes without impacts on biodiversity only if the previous dissidents - those stakeholders who have pushed forcibly in favour of the current mosquito control solution - namely the Department council and the mosquito control operator, accept replacing their solution with one based on mosquito traps. This requires that the Department council officially demand that the operator use the traps and not Bti. But this will be demanded only if the operator is convinced of the effectiveness of traps and is ready to use them. The operator has changed its practice many times in the sixty years over which mosquito control has been implemented in France, mainly because of prohibition of more and more phytosanitary products by European legislation. The operator is thus encouraged to test new registered products, as they did for Bti. It is now just starting to test mosquito traps and it remains to be seen whether it will adopt this method in the coming years, after a period of testing, appropriation and specific skills development.

\subsection{Proving impacts on biodiversity, again}

A second series of new developments since 2011 relates to the continuation of research about biodiversity impacts of Bti-based mosquito control. At first sight, the continuation of such research could be perceived as useless since impacts have already been proven, and since that proof has made no difference in terms of decision-making. However, two strategic challenges underpin these studies. First, confirming impacts of Bti and improving our understanding of them through long-term studies and extended data (such as the persistence of bacteria in soils) is necessary for continued participation of biodiversity scientists in local negotiations about mosquito control and its impacts. It reinforces the coalition of stakeholders that lobby for biodiversity in local policy-decisions. It contributes to the efforts of the actors who work to consolidate the social-technical network that would enforce the mosquito-trap based alternative to Bti.

Second, the compelling results about impacts of Bti from the 2006-2011 research programme have opened a new front of controversy in the scientific community dealing with mosquito-control. Biodiversity scientists continue to present their results at conservation conferences, but also now at conferences on mosquito-control where their results create vigorous debate.

"I was invited by the mosquito control association to its conference. Some scientists, generally financed by mosquito

control operators, were very vehement. In countries were mosquito control is less institutionalized, scientists

working with mosquito control companies worry about the consequence of detected impacts of Bti. In comparison,

The French participants had a very open-minded attitude". (Interview biodiversity scientist, 2016).

Participating in this controversy is all the more strategically import since advocates of Bti-based mosquito-control are also working to mobilize academic allies in their favour, such as scientific literature showing that Bti is harmless (Lagadic et al., 2014; Duchet et al., 2015). Proving the effect on biodiversity of Bti in the Camargue has been a remarkable step forward in academic terms. Even if it has been a disappointingly small step forward in terms of policy, continuing scientific research on this topic brings new insights into Bti impacts, but is also a necessity to prevent possible steps backwards, under pressure from the mosquito control community.

A third aspect of continuing research on Bti impacts is that it is increasingly affecting stakeholders at a larger scale. For example, the regional environmental administration does not have the administrative power to implement mosquito control for comfort reasons (this is controlled by the Department), but can authorize sanitary mosquito control operations. Administrators attest that the studies undertaken in the Camargue help them to clarify their own position and reject any abusive demands for mosquito control. 
"We were asked by the Department of $V$ ar to prepare a prefectural decree authorizing comfort mosquito control. I felt uncomfortable, so I contacted the [conservation research centre] as I had heard about their studies on Bti impacts. It enabled me to use their arguments and underpin the problem with Bti impacts" (Interview assistant director of PACA environmental administration, 2016).

Another interesting example is the new position of the Conservatoire du Littoral (the French coastal protection agency) relative to mosquito control. The Conservatoire du Littoral owns many natural coastal areas along the Mediterranean. With the exception of the Camargue, mosquito control has been continuously implemented in these areas since the 1960s, to the point that it has been taken for granted for decades. The new studies on Bti impacts in the Camargue have raised the interest of regional delegates, who have reformulated the problem with respect to their own mission:

"Can we question mosquito control in natural areas? Finally, the role of the Camargue is to push recognition of the fact that implementing mosquito control in natural spaces is not trivial" (Interview regional delegate, 2016).

Regional delegates therefore are starting to mobilize both their administrators and field managers.

"Looking from a historical perspective, people here have concentrated their efforts on artificialization issues initiated by the strong tourism development of the coast. Therefore, when I involved the Conservatoire du Littoral, I asked field managers about their management of the mosquito control issue. But this was not something they talked about. Now I try to raise this question again and develop a partnership with the mosquito-control operator and the French water agency" (Interview regional delegate, 2016).

"I know where I want to go: I consider that treatments should be avoided in all natural areas. This conviction is reinforced by results obtained in the Camargue [...]. I raised this point in our scientific committee four years ago and I intend to bring the issue up for debate again in the next meeting" (Interview regional delegate, 2016).

In short: the research results pertaining to Bti impact in the Camargue may not have clinched (yet) a change in mosquito-control policy there, but they have reopened both an academic debate on such impacts and, maybe more importantly, they have initiated, at the regional and national scale, a policy debate about mosquito control in conservation areas that had been closed for decades. The frustrating local policy impasse of 2011, leading biodiversity scientists to deepen research that had already provided conclusive results, is far from being useless after all. On the contrary, it appears strategic as it enables them to reinforce their position in the scientific community, prevents counteroffensives from Bti advocates and initiates a much wider advocacy network around the need for alternative mosquito-control solutions in view of biodiversity issues.

\section{Discussion}

The case study of mosquito-control in the Camargue eloquently illustrates the political dimension grounding sciences. As announced by Akrich et al. (2006), evidence is not just an objective description of the state of nature, but rests on a social construction process. Proven impacts of Bti on biodiversity will reach the status of evidence once concrete changes have been made based on those impacts, for instance if the alternative method for mosquito control is recognized as a necessary and satisfactory solution by a politically robust network of actors. In other terms, evidence from biodiversity science becomes compelling only as participants in the decision-making process recognize it as such by accepting their positions and decisions to be compelled by it.

\subsection{Strategic reflections for biodiversity scientists who want to make their research more compelling}

For biodiversity scientists who want the knowledge they produce to be taken up more by society to intensify and improve biodiversity policy, this means that their research and its impact play out in 
parallel, as they unfold simultaneously in the academic field and in the debates and action systems of action and policy.

As the processes of knowledge-acquisition, of network-building and of decision-making unfold alongside one another, at each stage scientists have to make, and do make, choices that are at the same time strategic in terms of producing knowledge (what do we want to prove exactly and how can we do it?), in terms of networks (who are our allies? And whose questions do our scientific questions echo?), and in terms of decision-making power processes (with whom do we negotiate? for what sort of commitments?). In making such strategic decisions, biodiversity scientists have to pay special attention to those allies that share their conservation goals (environmental NGOs, biodiversity policy agencies, etc.), but also to look for coalitions with others that have different goals (in our case for instance entrepreneurs interested in mosquito traps, or officials looking to reduce mosquito-control expenses). They also have to choose how they will relate to those who take opposite views and tend to act against conservation (Confront them? Dodge interactions? Collaborate?). All these strategic choices will have consequences both in terms of knowledge production (e.g. what questions will be answered, with what budgets) and of the impact of biodiversity research on decision-making.

This does not mean that the positions and roles of biodiversity scientists in decision-making are no different from those of other actors. Even if the political ground of science has long been established, a role-playing game is still occurring in which politicians attempt to show that they build their decision on an external science and in which environmental experts do not usually see themselves as political actors (Wesselink et al., 2013). As demonstrated by Rabaud et al. (this issue), this attitude of scientists distancing themselves from politics may not be so much a "naive vision" (as criticized by van den Hove, 2007) of the science-policy interface, as a form of strategic posturing, by which they respect the codes of their professional community in order to guarantee the legitimacy that grounds their ability to intervene in the network. Indeed, in the case of mosquito control in the Camargue, all the political leverage of biodiversity scientists' actions relied on their academic legitimacy. Therefore, biodiversity scientists have at the same time a limited set of possible forms of engagement (for example, legal action is generally not compatible), and real margins of manoeuvre for strategies that have important consequences, (for instance as science plays an important role in framing and defining environmental issues (Wesselink et al., 2013), or by forming explicit or implicit alliances that will affect both the content of research and policy choices).

Therefore it is their responsibility to build up an understanding and culture of strategic situations at the interface between biodiversity research and policy. As in other fields of strategy, case studies are essential bases for strategic learning and reflection (Yin, 2003). Based on the case of mosquitocontrol in the Camargue we would like to underline three points here.

First, innovations in techniques can be an important lever for biodiversity conservation. This is far from new in itself: biodiversity scientists often conclude their research by suggesting changes in technology and production systems, as they support agroforestry, permaculture, etc. But what sociology of innovation points to, and our case illustrates, is that there is a long way from the principle of an innovation to its being compelling enough to be adopted by a sufficient network of actors. As biodiversity scientists call for transformation in resource-management systems, this should be the beginning, not the end, of their engagement.

Second, it is tempting to see the impact of biodiversity research as a case of compelling knowledge swinging one crucial decision at a given moment in time. This is the kind of expectation that was frustrated by the Camargue officials as they reversed their commitment to stop Bti-based mosquito control if biodiversity impacts were demonstrated. A more realistic view is of decision-making as a continuous and complex process, which calls less for a big splash (although it can play a positive role) than for prolonged research that obstinately participates in the protracted struggles of 
biodiversity policy-making. A piece of knowledge from previous research may dry up on the shelf, while on-going research is a condition of biodiversity scientists having an on-going voice in the process of biodiversity policy-making. As showcased by the example of mosquito control in the Camargue, bridging the gap between scientific knowledge and policy-making does not occur through a simple set of predictable paths, but through multiple twists and turns that require from biodiversity scientists that they interpret unique field-specific political-scientific situations, and adapt their position and strategy accordingly.

Third, authors both in actor-network theory and in strategy insist on the fact that situations evolve rapidly: issues change, alliances and networks change, public, academic and political perceptions change. In the course of a few years, the biodiversity scientists in our case study have moved, as the situation evolved, from participating to a debate about authorizing Bti in the Camargue, to experimenting with mosquito traps and to participating in regional debates about mosquito control and national controversies on Bti. Negotiation is by nature a moving terrain. And as biodiversity scientists engage in biodiversity policy-making, the negotiation dynamics that underlie it requires from them successive choices that require intense strategic reflection. How can social scientists help?

\subsection{Where and how may social scientists may settle at the interface between biodiversity research and policy-making?}

Biodiversity scientists may find space for reflexivity and may improve their intervention through social science research that combines the detailed, case-specific analysis of science-policy processes and a strategic perspective centring on options available to actors who promote biodiversity conservation. We will underline here four points from our research.

First, our findings converge with Juntti et al. (2009), as they suggest that an understanding of power as contingent and vested in interaction amongst actors in specific material contexts could offer a significant methodological option for exposing the ways that actors attempt to engage knowledge to their advantage in the policy process (Law, 1998; Castree and MacMillan, 2001; Latour, 2004). Reversely, the production of scientific knowledge itself involves all kinds of social and cultural factors (Latour and Woolgar, 1979; Jasanoff, 2004) and is often driven by local, practical, and sometimes openly political interests (Wesselink et al., 2013). Therefore, the role of scientific evidence in policy-making process can be understood only by looking simultaneously at the production of scientific knowledge on the one hand and at the social and political context on the other (Juntti et al., 2009). In other words, just as biodiversity scientists have to invest in a better understanding of policy-making strategies, social scientists interested in helping biodiversity scientists contribute to conservation have to engage in understanding biodiversity science in the making at the same time as they investigate social and political processes.

Second, our conclusions meet the study by Bracken and Oughton (2012), which also demonstrates through an in-depth case study - although with a different theoretical background (Hajer, 2003) that the quality of knowledge as evidence is assumed after a long process of scrutiny and negotiations, involving professionals (their main focus), scientists, decision-makers and a variety of stakeholders. Both the trajectory of evidence in the actor network and the multiple and strategic dimensions of biodiversity scientists' interventions are better understood by studies based on an indepth and long-term field involvement. Such a long-term view enables, inter alia, to analyse the weight of uncertainty, which is a prominent characteristic of strategy in general, and of environmental policy in particular (Juntti et al., 2009) as it struggles to stay the course under often difficult social interests and power distribution. In our research on mosquito-control in the Camargue, we were struck by the fact that our observations from the 2011-2016 period allowed us to

gain a much deeper understanding of the processes in the 2006-2011 period than in our conclusions at the time (Guilet and Mermet, 2013), however striking they may have looked at the time. 
Third, given the complexity and divisiveness of the issues and processes of biodiversity policymaking, the position of the social scientists in relation to the actors is essential. Actor-network theory and strategic analysis promote different perspectives in that respect. ANT recommends symmetry (i.e. treating all protagonists, non-humans included) on an equal footing. Strategic analysis recommends choosing one concern (biodiversity) and those actors who give it high priority as the focal point of enquiry. We have combine both in this study by choosing biodiversity scientists as the focal point of our study over the years and embracing, rather than criticizing, their biodiversityconservation concerns, while at the same time being sensitive to the host of protagonists and the moving network that constitutes their strategic environment. Thus through our interviews and observations, we accompanied biodiversity scientists as they first negotiated the conditioning of mosquito control to the absence of impacts on biodiversity. Again, as they were frustrated by the decision of maintaining mosquito control, but moved on to support the development of the alternative solution with mosquito traps, started the tests of that innovation and communicated its potential to local officials. We shared their strategic reflexions as they considered breaking away from frustrating collaboration with officials, but adopted a collaborative position instead, acknowledging that nuisance reduction has to be managed to respond to the social demand, but insisting that it be achieved by innovations that reduce impact, and pushing on in the wider, regional and national emerging criticism of Bti treatment in wetlands.

Fourth and finally, our conclusions contradict views of the science-policy interface that simplify too much the picture by promoting general normative solutions. For instance it is not enough for biodiversity knowledge to be credible, relevant and legitimate (Cash et al., 2003): it also requires that it has been produced and shared in ways that enrol a powerful enough constituency of actors to make that knowledge compelling. Neither should the processes of enrolment and the ways in which knowledge creation is shared be viewed in ways that are too simple and normative. Calls to the consideration of local knowledge (Owens, 2005) and to participatory research (Fischer, 2002) are frequent and this tends to be formalized as a key attribute of formal organizations of science-policy interface (see Sarkki et al., 2015). Our case study of mosquito control in the Camargue encourages caution by recalling the power and vitality of the regular democratic institutions and process. Indeed, local inhabitants took part in the experimental mosquito control as beneficiaries and in the impact research program through a sociological survey. However, to influence decision in favour of establishing and then continuing mosquito control, they very actively addressed their elected local officials, formally or informally, using the representative democratic path. Active participation of stakeholders can take many different paths, beside participatory procedures. And most pointedly, it can play against biodiversity, rather than in favour of it. In the Camargue the involvement of local stakeholders has led officials in 2011 to reconsider their commitment to halting mosquito control if biodiversity impacts were demonstrated, and again in 2015, when they considered down phasing it for budgetary reasons. This confirms recent research on public participation that has shown that public involvement does not necessarily contribute to better environmental management, but has to be considered within the analysis of collective action for the environment as it unfolds in each field situation one considers (Salles and Mermet 2005).

ANT and strategic analysis converge in advocating in-depth, case-specific research, rather than readymade models of decision-making and action, because strategies, and the twists and turns of knowledge production and of decision-making take leverage in the unique features of each situation and, as they do so, change situations in ways that require continuous case-specific engagement in analysis and action. 


\section{References}

Adelle, C., Jordan, A., Turnpenny, J., 2012. Proceeding in parallel or drifting apart? A systematic review of policy appraisal research and practices. Environmental Planning C- Governance and Policy 30, 401-415.

Akrich, M., Callon, M., Latour, B. (eds.) 2006. Sociologie de la traduction : textes fondateurs, Paris, Mines ParisTech, les Presses, «Sciences sociales».

Billé, R., 2010. Action without change? On the use and usefulness of pilot experiments in environmental management. Sapiens, 3 (1), 1-6.

Bracken, L.J., Oughton E.A., 2012. Making sense of policy implementation: The construction and uses of expertise and evidence in managing freshwater environments. Environmental Science \& Policy 30, 10-18.

Bradshaw, G.A., Brochers, J.G., 2000. Uncertainty as information: narrowing the science-policy gap. Ecology and Society 4(7) (online).

Callon, M., 1986. Some elements of a sociology of translation: domestication of the scallops and the fishermen of St Brieuc Bay. First published in J. Law, Power, action and belief: a new sociology of knowledge? London, Routledge, 196-223.

Cash, D.W., Clark, W.C., Alcock, F., Dickson, N.M., Eckley, N., Guston, D.H., Jäger, J., Mitchell, R., 2003. Knowledge systems for sustainable development. PNAS 100, 8086-8091.

Castree, N., MacMillan, T., 2001. Dissolving dualisms: actor- networks and the reimagination of nature. In: Castree, N., Braun, B. (Eds.), Social Nature: Theory, Practice and Politics. Blackwell Publishing, Oxford, 208-224.

Charvolin, F., Frioux, S., Kamoun, L., Mélard, F., Roussel, I., 2015. La qualité de l'air entre perception et mesure: une approche socio-historique. In L. Mermet, D. Salles (Eds.) Environnement : la concertation apprivoisée, contestée, dépassée ? De Boeck, 323-338.

Claeys-Mekdade, C., Nicolas, L., 2009. Le moustique fauteur de trouble. Ethnologie française, XXXIX (1), 109-116.

Clark, W.C., Majone, G., 1985. The critical appraisal of scientific inquiries with policy implications. Science, Technology and Human Values 10 (3), 6-19.

Crozier, M., Friedberg, E., 1980. Actors and Systems. The Politics of Collective Action. The University of Chicago Press, Chicago.

Duchet, C., Franquet, E., Lagadic, L., Lagneau, C., 2015. Effects of Bacillus thuringiensis israelensis and spinosad on adult emergence of the non-biting midges Polypedilum nubifer (Skuse) and Tanytarsus curticornis Kieffer (Diptera: Chironomidae) in coastal wetlands. Ecotoxicology and Environmental Safety 115, 272-278.

Fischer, F., 2002. Citizens, Experts and the Environment. Duke University Press, Durham.

Gordon, J.E., 2006. The role of science in NGO mediated conservation: insights from a biodiversity hotspot in Mexico, Environmental Science \& Policy 9 (6), 547-554.

Guillet, F., Mermet, L. 2013. L'expertise, composante essentielle mais insuffisante des stratégies pour la biodiversité: le cas de la démoustication en Camargue (France). VertigO 13, (Online).

Hajer, M., 2003. Policy without polity? Policy analysis and the institutional void. Policy Sciences 36, 175-195.

Jacob, C., Poulin, B., 2016. Indirect effects of mosquito control using Bti on dragonflies and damselflies (Odonata) in the Camargue. Insect conservation and diversity 9 (2), 161-169.

Jasanoff, S. (Ed.), 2004. States of Knowledge: The Co-Production of Science and Social Order. Routledge, London.

Juntti, M., Russel, D., Turnpenny, J., 2009. Evidence, politics and power in public policy for the environment. Environ Science and Policy 12, 207-215. 
Lagadic, L., Roucaute, M., Caquet, T., 2014. Bti sprays do not adversely affect non-target aquatic invertebrates in French Atlantic coastal wetlands. Journal of Applied Ecology 51(1), 102-113.

Latour, B., Woolgar, S., 1979. Laboratory Life: The Construction of Scientific Facts. Princeton University Press, Princeton.

Latour, B. 1987. Science to action. How to Follow Scientists and Engineers Through Society, Harvard University press.

Latour, B., 2004 Politics of Nature. How to Bring the Sciences into Democracy. Harvard University Press.

Latour, B., 2005. Reassembling the Social: An Introduction to Actor-Network-Theory. UK: Oxford University Press.

Law, J., 1998. After ANT: complexity, naming and topology. In: Law, J., Hassard, J. (Eds.), The Actor-Network Theory and After. Blackwell.

Loreau, M., 2006. Diversity without representation. Nature 442, 245-246.

Lorino, P., Tarondeau, J-C., 2006. De la stratégie aux processus stratégiques. Revue française de gestion 32, 307-328.

Mermet, L., 2011. Strategic Environmental Management Analysis: Addressing the Blind Spots of Collaborative Approaches. IDDRI, Paris (France).

Olivier de Sardan, J-P., 1995. La politique du terrain. Sur la production des données en anthropologie. Enquête 1, 71-109.

Owens, S., 2005. Commentary: making a difference? Some perspectives on environmental research and policy. Transactions of the Institute of British Geographers 30, 287-292.

Poulin B., 2015. Bilan de l'expérimentation des pièges BAM au Sambuc en 2015.

Poulin, B., Lefebvre, G., Duborper, E., Paz, L., 2010b. Résultats du suivi de l'impact potentiel des traitements au Bti sur les invertébrés paludicoles et les hirondelles des fenêtres en Camargue pour la période 2006-2009, Rapport Tour du Valat, 20 p.

Poulin, B., Lefebvre, G., Paz, L., 2010a, Red flag for green spray: adverse trophic effects of Bti on breeding birds. Journal of Applied Ecology 47, 884-889.

Salles, D. Mermet, L., 2015. Conclusion générale. In L., Mermet, and D., Salles (Eds.), Environnement : la concertation apprivoisée, contestée, dépassée ? De Boeck, Paris, 359-368.

Sarkki, S., Tinch, R., Niemelä, J., Heink, U., Waylen, K., Timaeus, J., Young, J., Watt, A., Neßhöver, C., van den Hove, S., 2015. Adding 'iterativity' to the credibility, relevance, legitimacy: A novel scheme to highlight dynamic aspects of science-policy interfaces. Environmental Science \& Policy 54, 505 - 512.

Takacs, D., 1996. The Idea of Biodiversity: Philosophies of Paradise. Johns Hopkins University Press, Baltimore and London.

van den Hove, S. 2007. A rational for science-policy interfaces. Futures 39, 807-826.

Wesselink, A., Buchanan, K., Georgiadou, Y., Turnhout, E., 2012. Technical knowledge, discursive spaces and politics at the science-policy interface. Environmental Science and Policy 30, 1-9.

Yin, K.R., 2003. Case study research, design and methods. 3rd ed., vol. 5. Thousand Oaks, Sage. 